\title{
Cellular automaton simulation of microstructure evolution during austenite decomposition under continuous cooling conditions
}

\author{
M R VARMA*, R SASIKUMAR, S G K PILLAI and P K NAIR \\ Regional Research Laboratory, Trivandrum 695 019, India \\ Department of Metallurgical Engineering, Indian Institute of Technology, Chennai 600 036, India
}

MS received 8 February 2001; revised 23 March 2001

\begin{abstract}
A two-dimensional diffusion based model is developed to describe transformation of austenite into ferrite and pearlite under continuous cooling conditions. The nucleation of ferrite is assumed to occur over grain boundaries and the nucleation of pearlite is assumed to be taking place all over the grain and at growing ferrite-austenite interfaces, when the composition and temperature conditions are favourable. A cellular automaton algorithm, with transformation rules based on this model is used for the growth of ferrite and pearlite. Model predicted results for continuous cooling transformations are verified by comparing the model predicted microstructure features with the experimental measurements for two sets of plain carbon steels of different composition and austenite grain size. Using the model, it is possible to generate results like undercooling to start ferrite and pearlite transformations, which are difficult to obtain experimentally.
\end{abstract}

Keywords. Microstructure modeling; CCT diagrams; austenite; ferrite; pearlite; nucleation and growth.

\section{Introduction}

Computer simulation methods to predict microstructure evolution during heat treatment processes have received considerable attention during recent years. The simulations aim at quantitative prediction of thermal, microstructural and mechanical properties of materials subjected to given heat treatment processes. The predictions are based on mathematical models, which link basic principles of heat and mass transfer and microstructural models, to the operating process parameters. Several researchers like Agarwal and Brimacombe (1981), Denis et al (1985, 1987, 1992), Hawbolt et al (1985), Campbell et al (1991), have developed semi empirical models for the study of microstructure evolution during heat treatment of steels. These models use experimentally obtained time-temperaturetransformation (TTT) data for predicting the volume fractions of different phases evolved during a heat treatment process. While capable of excellent predictions in cases where reliable transformation data is available, they suffer from several limitations like: (i) the need for extensive amount of experimental data, since the transformation is very sensitive to preprocessing, compositional and microstructural changes of the parent material and (ii) no information can be obtained on the morphology and distribution of the resulting phases and these simulations cannot give rise to any deeper understanding of the underlying mechanisms.

\footnotetext{
*Author for correspondence
}

In an attempt to overcome some of these limitations Kumar et al (1998) developed a model for transformation of austenite into ferrite, which considers the mechanisms of transformation such as nucleation and diffusion controlled growth of ferrite. This model is also semiempirical in that, the nucleation is modelled empirically without considering the underlying atomistic phenomena but growth is modelled by rigorously solving the mass transfer equations for carbon. The model was implemented using the cellular automaton technique and with this it was possible to get considerable insight into the early competition between nucleation and early growth of ferrite and reproduce most of the experimental results obtained by Militzer et al (1996) who studied the transformation under continuous cooling conditions. However, the nucleation and growth of pearlite was not modelled in detail. In this paper, these problems are solved. One of the main drawbacks of the model developed by Kumar et al (1998) is the assumption of instantaneous nucleation. Nucleation was assumed to take place instantaneously at specific undercoolings. However, it is known from Andrews (1965) that for any transformation, there is an incubation time for the nuclei to form and the model by Kumar et al (1998) neglects this. Hence in the present model there is a time dependence for the nucleation in addition to the temperature dependence. The model also considers the growth of pearlite by cooperative growth of ferrite and carbide. The model is experimentally verified by the measurements of microstructures formed on plain carbon steels with $0.28 \% \mathrm{C}$ and $0.38 \% \mathrm{C}$, subjected to different heat treatments. 


\section{Nucleation model}

The phenomena of austenite transformation into ferrite and pearlite, during the initial stages of transformation, resemble very much to the grain structure formation during solidification of alloy melts. To model the nucleation and growth during solidification of alloy melts, the continuous nucleation model proposed by Thevoz et al (1989) was used successfully. Because of the similarity between the processes, the same model was attempted by the authors in an earlier paper by Kumar et al (1998). In the continuous nucleation model proposed by Thevoz et al (1989), nucleation density was determined from $\Delta T$ $-\mathrm{d} N / \mathrm{d} \Delta T$ gaussian, with the help of 3 adjustable parameters. Thevoz et al (1989) also indicated that the relation between $\Delta T-N$ is exponential and this relation is used in the present model for the determination of nucleation density. It is assumed that the grain boundary has a number of groups of potential ferrite nucleation sites, each of which becomes active when an associated undercooling is reached and the time spent at this undercooling exceeds the incubation time relevant to that particular temperature. For continuous cooling transformations, the fractional incubation time for all temperatures below the equilibrium transformation temperature are summed up. Nucleation is allowed to take place when this sum just exceeds unity. The pearlite nucleation is modelled on the same lines as for ferrite described above. Randomly chosen sites in the grain are attributed with specific undercoolings for the activation of pearlite nucleation. As the carbon concentration in austenite increases and the temperature decreases, locations within the grain become undercooled with respect to the formation of pearlite. The undercooling with respect to carbide formation is calculated as,

$$
\Delta T_{\text {pearlite }}=\left(T_{\mathrm{Ac} 3}+m_{\text {hyper }} \cdot C_{\text {aust }}^{*}\right)-T
$$

where $m_{\text {hyper }}$ is the slope of the hypereutectoid line in the $\mathrm{Fe}-\mathrm{Fe}_{3} \mathrm{C}$ equilibrium diagram and $T$ the current temperature.

A simple exponential variation of number of nuclei, $N$ with undercooling $\Delta T$ is assumed for both ferrite and pearlite. For the incubation times $\left(t_{\text {inc }}\right)$, a power law dependence on temperature is assumed as shown in (2) and (3) below

$$
\begin{aligned}
& N(\Delta T)=a \exp (b \Delta T), \\
& t_{\mathrm{inc}}=c(T)^{d},
\end{aligned}
$$

where $a, b, c$ and $d$ are adjustable parameters, which can be fitted with the help of a few experimentally measured values.

\section{Model for growth of ferrite and pearlite}

The growth of ferrite is assumed to be controlled by the diffusion of carbon in austenite. Equilibrium conditions are assumed at the austenite ferrite interface and the interface movement is controlled by solute balance at the interface.

During the ferrite transformation, the average carbon concentration in a cell varies due to diffusion and is calculated by solving the finite difference form of the Fick's equation. Ferrite growth continues until the diffusion becomes much too slow due to the fall in temperature or when pearlite nucleates in front of the growing ferriteaustenite interface and prevents further growth.

The ferrite growth is stopped once the $\Delta T_{\text {pearlite }}$ exceeds specified undercooling for the nucleation of pearlite and the incubation condition for pearlite nucleation is satisfied.

Zener (1946) and Hillert (1957) have established theories of pearlite growth in plain carbon steels. On the basis of the Hillert (1957) model, Munirajulu et al (1994) have modelled the growth of pearlite. They have given following expressions for growth velocity.

$$
\begin{aligned}
V= & 2.94 \times 10^{-2} \exp \left(-Q_{\mathrm{v}} / R T\right)(\Delta T)^{2} \mathrm{~m} / \mathrm{S} \\
& \text { for volume diffusion, }
\end{aligned}
$$

and

$$
\begin{aligned}
V= & 2 \cdot 6 \times 10^{-7} \exp \left(-Q_{\mathrm{B}} / R T\right)(\Delta T)^{3} \mathrm{~m} / \mathrm{S} \\
& \text { for boundary diffusion. }
\end{aligned}
$$

For $\mathrm{Fe}-\mathrm{C}$ system diffusion coefficients are assumed by Munirajulu et al (1994) as

$$
\begin{aligned}
D_{\mathrm{C}}^{\gamma}= & 0 \cdot 12 \times 10^{-4} \exp \left(-Q_{\mathrm{v}} / R T\right) \mathrm{m}^{2} / \mathrm{S} \\
& \text { for volume diffusion, }
\end{aligned}
$$

and

$$
\begin{aligned}
D_{\mathrm{B}}= & 7.9 \times 10^{-7} \exp \left(-Q_{\mathrm{B}} / R T\right) \mathrm{m}^{2} / \mathrm{S} \\
& \text { for boundary diffusion control. }
\end{aligned}
$$

\section{Cellular automaton implementation of the model}

The computation domain is a single austenite grain. The boundary of the computational domain is the grain boundary region and ferrite nucleation is assumed to take place in this region only. The domain is adiabatic to carbon diffusion. Pearlite nucleation takes place at the austeniteferrite interfaces or in the bulk of the grain if the conditions for nucleation are favourable.

The simulations have been performed in two dimensions on a square grid. The grain boundary is the onedimensional outline of the square; but it is not implied by this that the shape of the grain boundary section is square. The square has been chosen so that it is easy to divide the 
grain into square cells for performing finite difference solution of the diffusion equation. Equidistant nodes distributed on the grain boundary line depict potential nucleation sites for ferrite. The nodes divide the grain boundary into one-dimensional cells for simulating the growth of the nuclei along the grain boundary.

Each cell is associated with a state variable which represents the phase inside this cell. The state variable 1 denotes untransformed austenite. When a potential ferrite nucleation site becomes activated, its state variable is changed to 2 depicting that this cell now contains a ferrite-austenite interface. After this ferrite growth is simulated in this cell, pearlite nucleation can take place either in front of the ferrite-austenite interface due to the accumulation of carbon there, or in bulk cells. Thus pearlite nucleation takes place either in cells of state variable 2 or 1 . When the pearlite nucleation conditions are satisfied, the state variable is changed to 3 . Thereafter this cell goes into the pearlite growth mode. A cell in which the austenite has completely transformed to ferrite has a state variable 4 and a cell where the austenite has completely transformed to pearlite or a mixture of ferrite and pearlite has a state variable 5 .

The first step in the simulation is the assignment of an activation undercooling for ferrite nucleation, to the grain boundary cells and for pearlite nucleation to the bulk cells. For each value of the undercooling, the probability of nucleation in a cell is calculated from (2). If the probability is sufficient for the nucleation, this value of the undercooling is assigned to the cell as its activation undercooling.

When the transformation under continuous cooling conditions is simulated, temperature is reduced at a specified rate and at each temperature the fractional incubation time is calculated and summed. When the undercooling associated with a cell is exceeded, and the total fractional incubation time exceeds 1 , ferrite or pearlite is nucleated and further growth will take place as per the corresponding growth model.

Every cell in the system is characterized by the state variable, carbon concentration in austenite, carbon concentration in ferrite, average concentration, fraction of ferrite, and fraction of pearlite. The phase-state variable can be $1,2,3,4$ or 5 whose meanings were described earlier. The initial state of the system has phase-state variable $=1$, carbon concentration $=\mathrm{C}_{0}$, ferrite fraction $=0$, pearlite fraction $=0$, and average carbon concentra- tion $=\mathrm{C}_{0}$. When the temperature is lowered and/or as time proceeds, ferrite nucleation takes place in some of the cells on the grain boundary. These start growing immediately with a velocity, which can be calculated by

$$
V=D\left(\mathrm{dC}_{\text {aust }} / \mathrm{d} n\right)\left(1 /\left(\mathrm{C}_{\text {aust }}^{*}\left(1-k_{\mathrm{p}}\right)\right)\right.
$$

The above equation can be derived by a simple solute balance on a planar interface and details are given by Kurtz and Fischer (1986). In above equation $\mathrm{dC}_{\text {aust }} / \mathrm{d} n$ is the concentration gradient perpendicular to the interface and the interface carbon concentration, $C^{*}$ is given by the phase diagram value for austenite concentration corresponding to the current temperature, $k_{\mathrm{p}}$ the partition coefficient of carbon between austenite and ferrite and $D$ the diffusion coefficient for carbon in austenite.

The phase-state variable of a cell in which there is a ferrite-austenite interface is given a phase-state variable of 2, and of a cell with austenite - pearlite interface is given a phase state variable 3 . The position of the interface is tracked knowing the velocities in each transforming cell. Knowing the position of the interface, the fraction of ferrite or pearlite in each transforming cell can be calculated.

The change in carbon concentration in the cells during ferrite growth is calculated using Fick's equation with a source term coming from the phase transformation of austenite to ferrite viz.

$$
\mathrm{C}_{\mathrm{aver}}=\mathrm{C}_{\mathrm{ferr}} V_{\alpha}+\left(1-V_{\alpha}\right) \mathrm{C}_{\mathrm{aust}},
$$

and

$$
\mathrm{C}_{\mathrm{ferr}}=k_{\mathrm{p}} * \mathrm{C}_{\mathrm{aust}} \text {. }
$$

Knowing $\mathrm{C}_{\text {aver }}(t+\mathrm{d} t)$ from the diffusion equation and $V_{\alpha}(t+\mathrm{d} t)$ in every cell, $\mathrm{C}_{\text {aust }}(t+\mathrm{d} t)$ and $\mathrm{C}_{\text {ferr }}(t+\mathrm{d} t)$ are calculated. When the ferrite fills a cell, its phase-state variable is changed to 3 .

During pearlite growth there is only lateral redistribution of carbon between the lamellae and, therefore, pearlite growth does not give rise to changes in carbon concentration in the cells. The concentration of the cells with growing pearlite is assumed to remain at the eutectoid concentration.

The simulation is stopped on crossing the martensitic transformation start temperature $M_{\mathrm{s}}$ or on complete transformation of the austenite.

Table 1. The constants used in the model.

\begin{tabular}{ll}
\hline Constant & \multicolumn{1}{c}{ Value } \\
\hline Diffusion constant (bulk) & $0.12 \times 10^{-4} \exp (-125000 / R T)$ \\
Diffusion coefficient (grain boundary) & $7.9 \times 10^{-7} \exp (-110000 / R T)$ \\
Maximum carbon solubility in ferrite & 0.025 \\
Partition coefficient of carbon between austenite and ferrite & 0.0925 \\
\hline
\end{tabular}



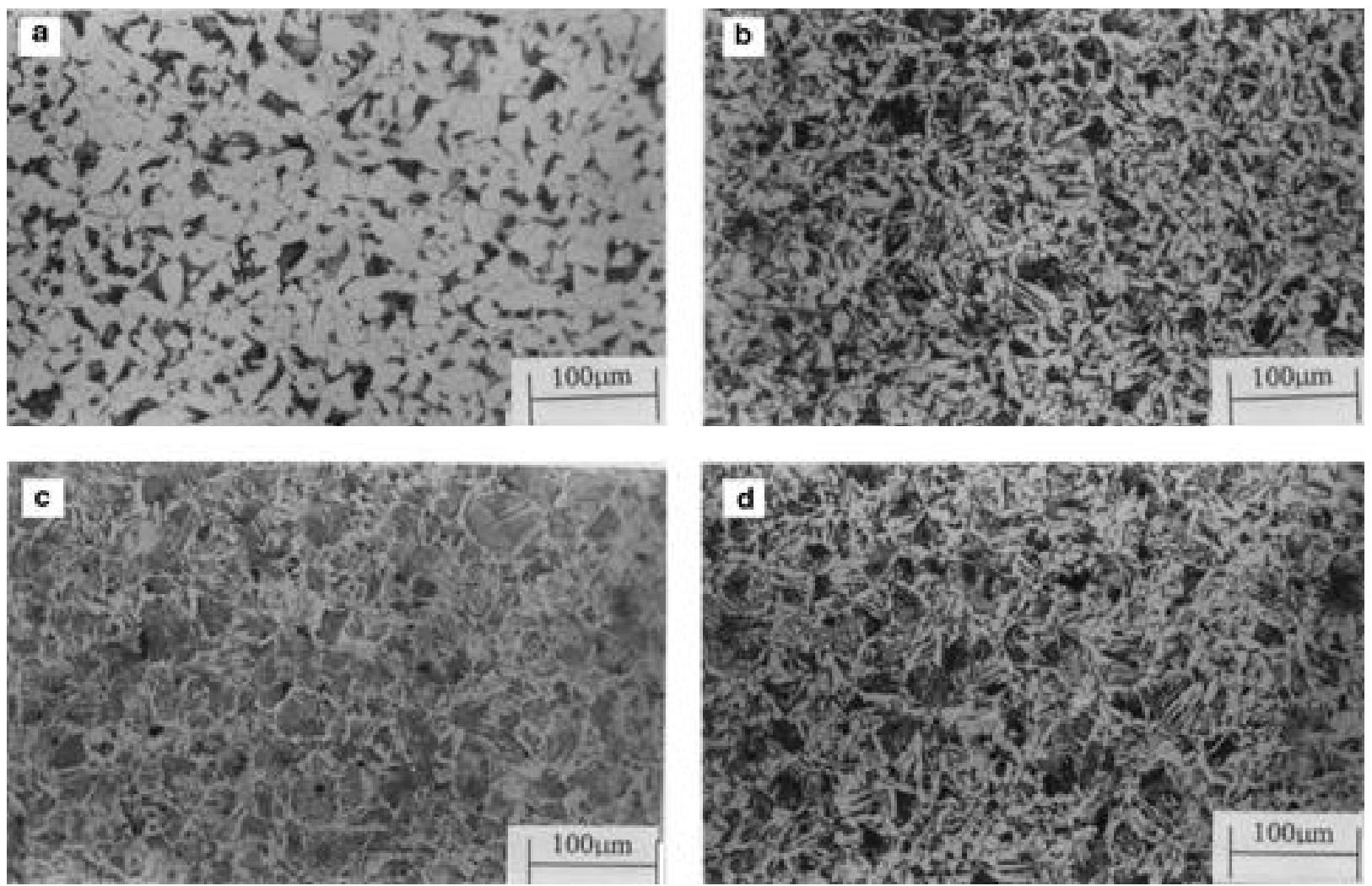

Figure 1. Microstructures of $0 \cdot 28 \% \mathrm{C}$ steel heat treated samples: a. cooling rate $1.75^{\circ} \mathrm{C} / \mathrm{S}$ and equivalent grain diameter $d_{\alpha}=13.05 \mu \mathrm{m}$, b. cooling rate $30.07^{\circ} \mathrm{C} / \mathrm{S}$ and equivalent grain diameter $d_{\alpha}=9.86 \mu \mathrm{m}$, c. cooling rate $37.00^{\circ} \mathrm{C} / \mathrm{S}$ and equivalent grain diameter $d_{\alpha}=9.7 \mu \mathrm{m}$ and $\mathbf{d}$. cooling rate $62.53^{\circ} \mathrm{C} / \mathrm{S}$ and equivalent grain diameter $d_{\alpha}=8.29 \mu \mathrm{m}$.

Table 2. Compositions of the steels used for the experimental verification of the model.

\begin{tabular}{ccccccccccc}
\hline $\mathrm{C}$ & $\mathrm{Si}$ & $\mathrm{Mn}$ & $\mathrm{P}$ & $\mathrm{S}$ & $\mathrm{Cr}$ & $\mathrm{Mo}$ & $\mathrm{Ni}$ & $\mathrm{Cu}$ & $\mathrm{V}$ & $\mathrm{Co}$ \\
\hline 0.28 & 0.22 & 0.48 & 0.06 & 0.07 & 0.14 & 0.02 & 0.15 & 0.18 & 0.012 & 0.005 \\
0.38 & 0.09 & 0.89 & 0.04 & 0.04 & 0.02 & Nil & Nil & 0.01 & Nil & Nil \\
\hline
\end{tabular}

The grid size used in these simulations is $1 \mu \mathrm{m}$. The constants used are given in table 1 . The adjustable parameters are given in table 3 . The simulation variables are the cooling rate and the austenite grain size.

\section{Experimental}

Plain carbon steels with $0 \cdot 28 \% \mathrm{C}$ and $0 \cdot 38 \% \mathrm{C}$ were used for the experimental studies. The exact composition of the above steels are given in table 2 .

The first step in the experiment was the calibration of the steel samples. A steel can be considered as calibrated if its composition and austenite grain size are known. The compositions of the steels were analysed using Direct Reading Vacuum Emission Spectroscope (A.R.L Ltd, USA). Measurement of prior austenite grain size was done by Jeffries planimetric method [ASTM E-112] and the results were compared with the results obtained by
Table 3. Adjustable parameters used in the model.

\begin{tabular}{ll}
\hline Parameters for ferrite nucleation & \multicolumn{1}{c}{ Value } \\
\hline a & $3.5 \times 10^{7}$ \\
b & 0.0025 \\
c & $1.4 \times 10^{-3}$ \\
d & 52.63 \\
\hline Parameters for pearlite nucleation & Value \\
\hline a & $2.0 \times 10^{9}$ \\
b & 0.00009 \\
c & $1.46 \times 10^{-3}$ \\
d & 17.92 \\
\hline
\end{tabular}

intercept method. Measured ASTM grain size number for $0.28 \% \mathrm{C}$ steel is 8.5 which corresponds to an average austenite grain area of $356 \mu \mathrm{m}^{2}$ and for $0.38 \% \mathrm{C}$ steel is 4.5 which corresponds to an average grain area of $5700 \mu \mathrm{m}^{2}$. 

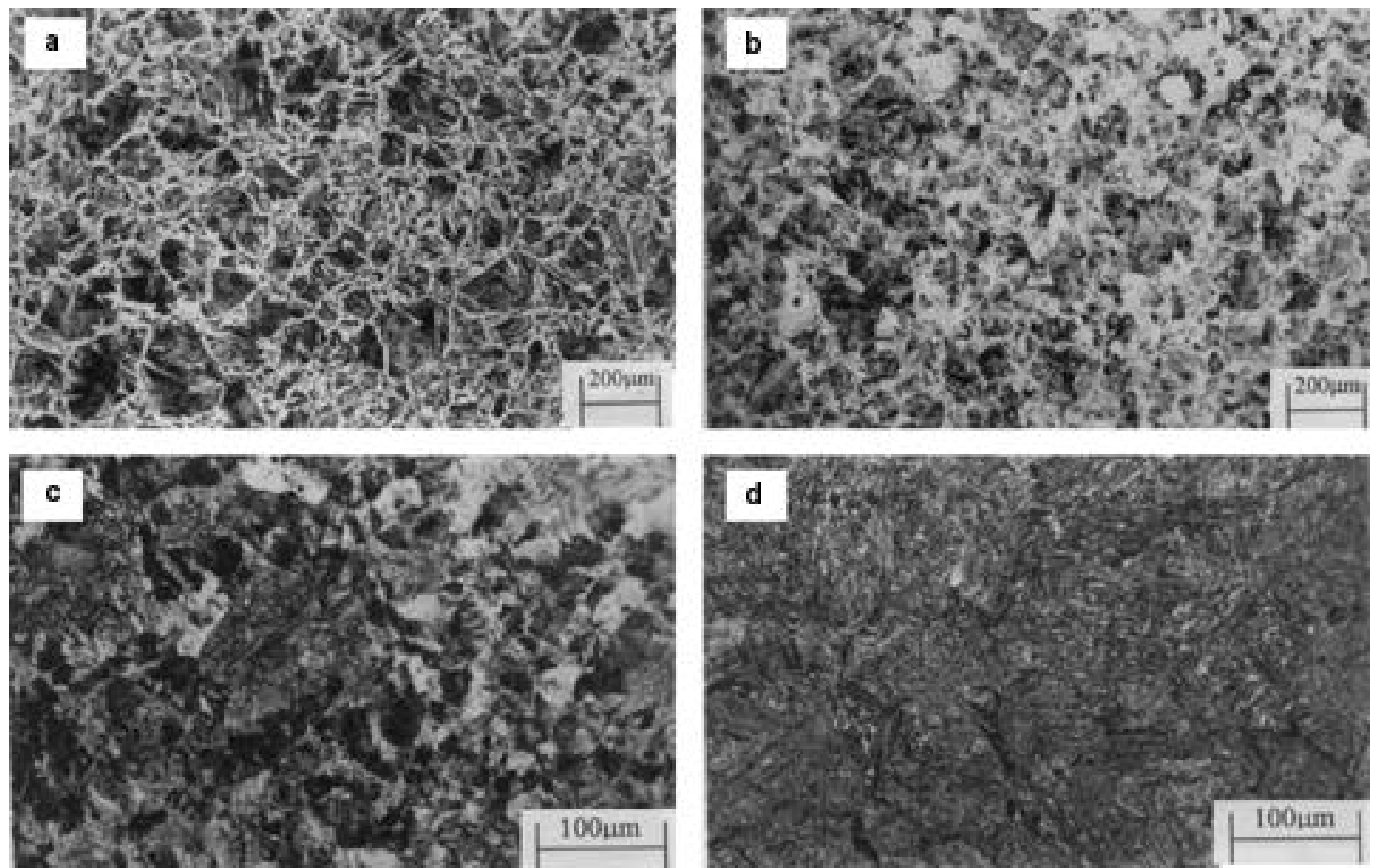

Figure 2. Microstructures of $0.38 \% \mathrm{C}$ steel heat treated samples: a. cooling rate $1.98^{\circ} \mathrm{C} / \mathrm{S}$ and equivalent grain diameter $d_{\alpha}=13.05 \mu \mathrm{m}, \mathbf{b}$. cooling rate $19.15^{\circ} \mathrm{C} / \mathrm{S}$ and equivalent grain diameter $d_{\alpha}=7.87 \mu \mathrm{m}$, c. cooling rate $37.37^{\circ} \mathrm{C} / \mathrm{S}$ and equivalent grain diameter $d_{\alpha}=4.66 \mu \mathrm{m}$ and $\mathbf{d}$. cooling rate $91.48^{\circ} \mathrm{C} / \mathrm{S}$ and equivalent grain diameter $d_{\alpha}=4.37 \mu \mathrm{m}$.

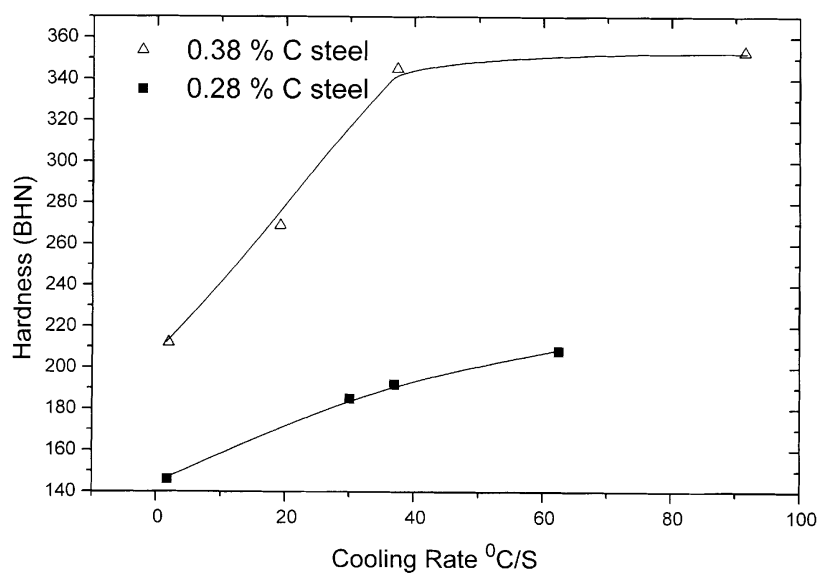

Figure 3. Experimentally observed variation of hardness (BHN) with cooling rate for $0.28 \%$ and $0.38 \% \mathrm{C}$ steels.

The steels were received as rods of $2.54 \mathrm{~cm}$ diameter. $2.54 \mathrm{~cm}$ long samples for heat treatment were cut from these steel rods. At the centre of the sample a thermocouple was mechanically fixed. The samples were then heated to the austenitizing temperature. About $1 \mathrm{~h}$ soaking time was given at the austenitizing temperature. The samples were cooled at different cooling rates to room temperature. The temperatures during the transformation

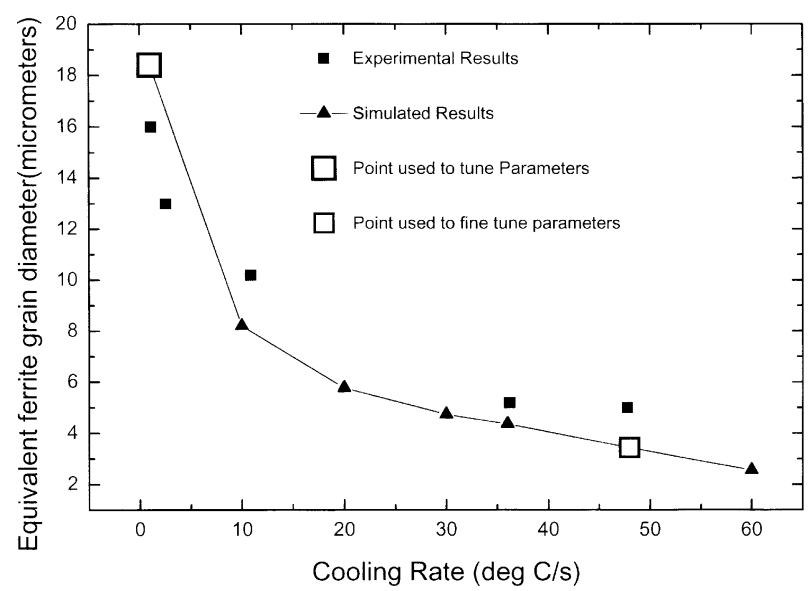

Figure 4. Variation of the equivalent grain diameter with cooling rate for $0.28 \% \mathrm{C}$ steel of ASTM grain size no. 8.5 (comparison of modelled and experimental results).

were recorded during all heat treatment processes. Different cooling rates were achieved by cooling the samples in furnace, air, forced air blow, water spray, ice and water. The samples were sectioned at positions close to the thermocouple attached in the sample and prepared for metallography. The metallography was done using an Olympus BX-40 model microscope to which an image analysis system was attached. The software used for 
image analysis was CLEMEX VISION. Details of the image analysis software is available in the Clemex Vision Users Guide (1998).

\section{Results and discussion}

Important parameters measured in the experiments include the cooling rate, ferrite fraction, pearlite fraction, number of ferrite grains, and equivalent ferrite grain diameter of the samples cooled at different cooling rates. The equivalent grain size is the ratio of the ferrite fraction (area occupied by ferrite grains in microstructure) and the number of ferrite grains present (in that microstructure area). Both ferrite fraction and the number of ferrite grains are measured using the image analyzer mentioned before.

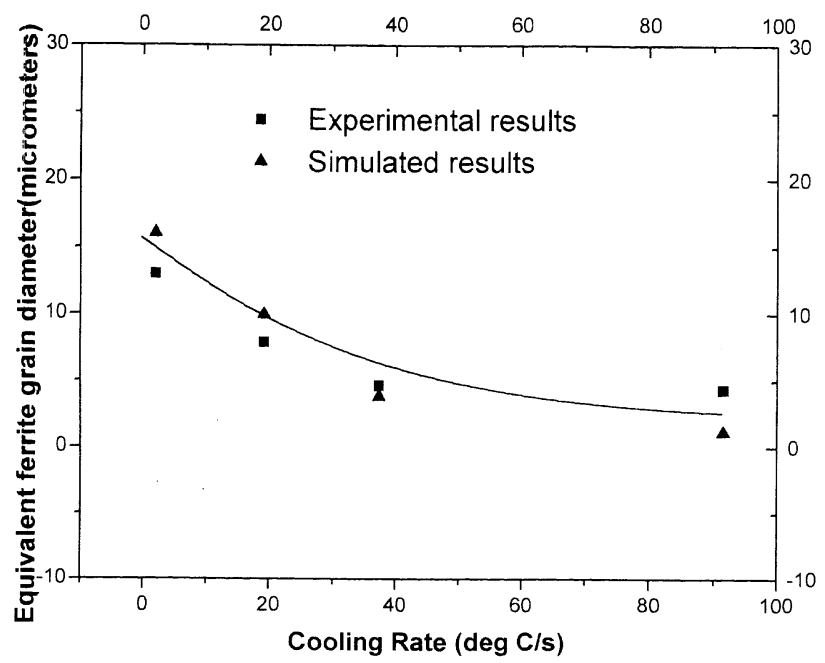

Figure 5. Variation of equivalent grain diameter with cooling rate for $0.38 \% \mathrm{C}$ steel of ASTM grain size no. 4.5 (comparison of modelled and experimental results).

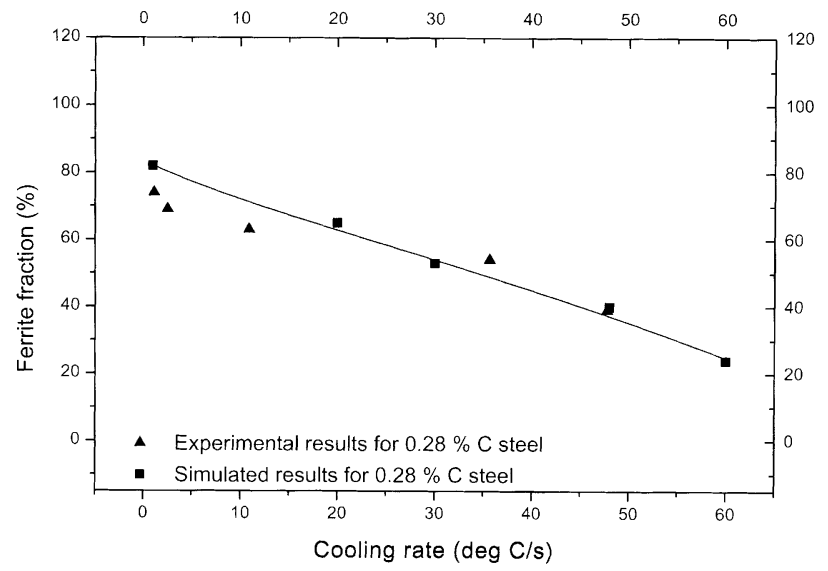

Figure 6. Variation of the ferrite fraction with cooling rate for $0.28 \% \mathrm{C}$ steel of ASTM grain size no. 8.5 (comparison of modelled and experimental results).
Microstructures of $0.28 \% \mathrm{C}$ steel and $0.38 \% \mathrm{C}$ steel samples, cooled from austenizing temperatures at different cooling rates are shown in figures 1 and 2, respectively. Microstructure of these samples shows that the fraction of ferrite and pearlite vary with cooling rate. Hardness of the samples cooled at different cooling rates are plotted in figure 3 for 0.28 and $0.38 \% \mathrm{C}$ steels. As expected, the hardness is found to increase, for both steels, with cooling rate due to the presence of more pearlite as seen from figures 1 and 2 .

In the model, it was possible to determine the total ferrite fraction, total pearlite fraction, and the number of ferrite grains nucleated. From these, equivalent ferrite grain diameter, was determined. The adjustable parameters of the model were tuned to get the correct equivalent grain diameter value at any one cooling rate and then

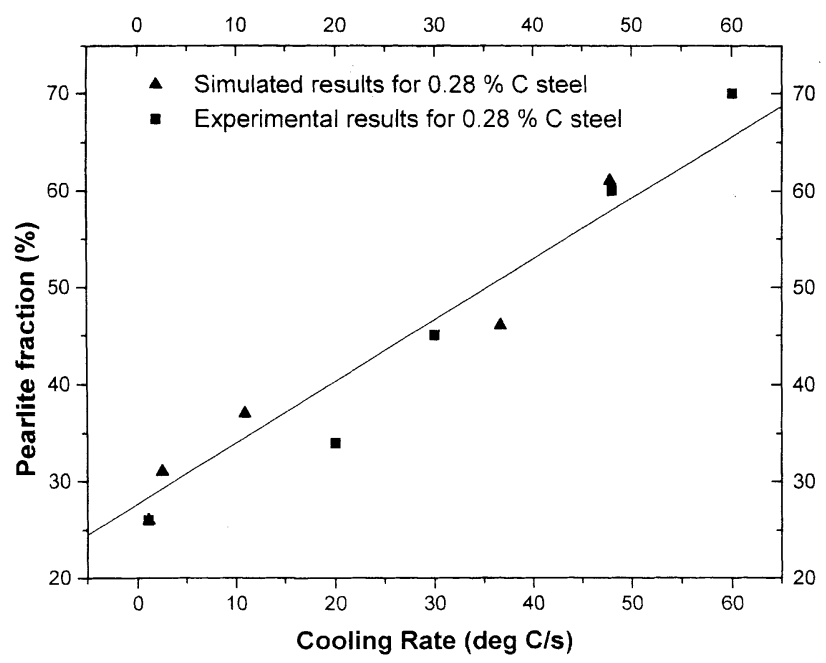

Figure 7. Variation of the pearlite fraction with cooling rate for $0.28 \% \mathrm{C}$ steel of ASTM grain size no. 8.5 (comparison of modelled and experimental results).

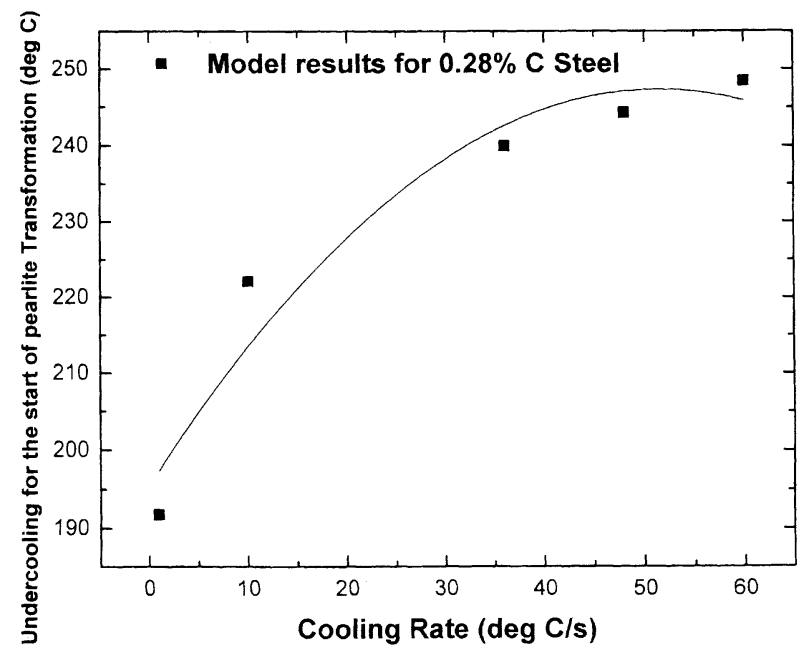

Figure 8. Simulated variation of the undercooling for the start of ferrite transformation with cooling rate. 


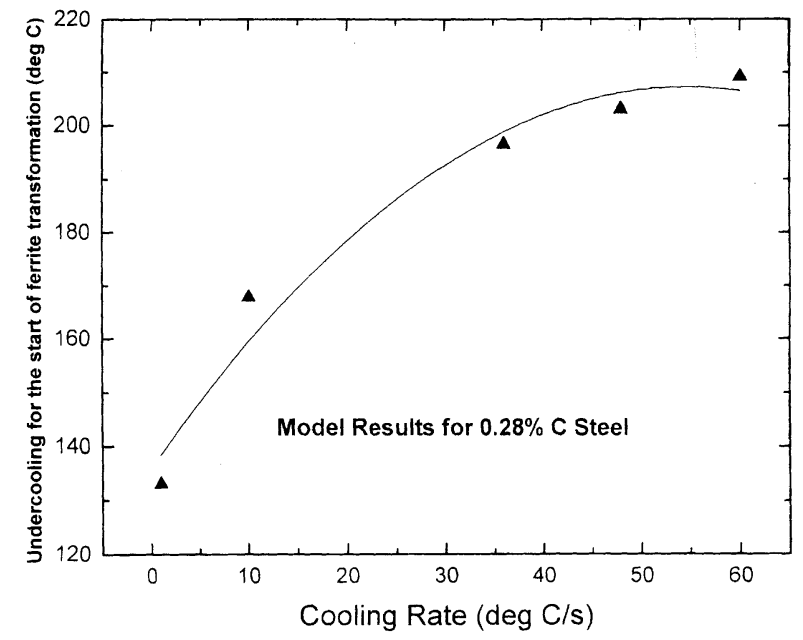

Figure 9. Simulated variation of the undercooling for the start of pearlite transformation with cooling rate.

fine tuned to reproduce the values at a second cooling rate. Then using the same parameters, the equivalent ferrite grain diameter, for all cooling rates were determined. This is plotted in figure 4 for $0.28 \% \mathrm{C}$ steels and figure 5 for $0.38 \% \mathrm{C}$ steels. It can be seen that the ferrite becomes finer on increasing the cooling rate as $d_{\alpha}$ decreases with increasing cooling rate. Variation of ferrite fraction and pearlite fraction with cooling rate is shown in figures 6 and 7. It can be seen from figures 4-7 that the simulated and experimental results agree for both $0.28 \% \mathrm{C}$ and $0.38 \% \mathrm{C}$ steels having the grain size of ASTM no. 8.5 and 4.5 respectively. Apart from the above results, the model can predict other results like variation of undercooling for the start of ferrite and pearlite transformations with cooling rate which are difficult to be obtained experimentally. Figures 8 and 9 show the simulated variation of the undercooling for the start of transformation for ferrite and pearlite transformations with cooling rate.

Using the cellular automaton technique (used in the modelling), it is possible to follow the transformation process by continuously following the state variables. The state variable 1 represents a cell with untransformed austenite; 2, austenite + ferrite; 3, austenite + ferrite + pearlite; 4 , complete ferrite; 5 , complete pearlite. In the austenite decomposition programme, the ferrite grain grown from different ferrite nucleii are given separate identification numbers. For example, if a cell is completely transformed to ferrite by the growth from nucleii no.2, the cell will have a state variable of 4 representing the ferrite and a grain identification number 2 . Using the state variables, at the end of the transformation, the visual representation of the transformed microstructure is possible. A separate programme plots each cell having the state variable 5 (pearlite) as black and cells having state variable 4 (ferrite) by different colours like blue, green,
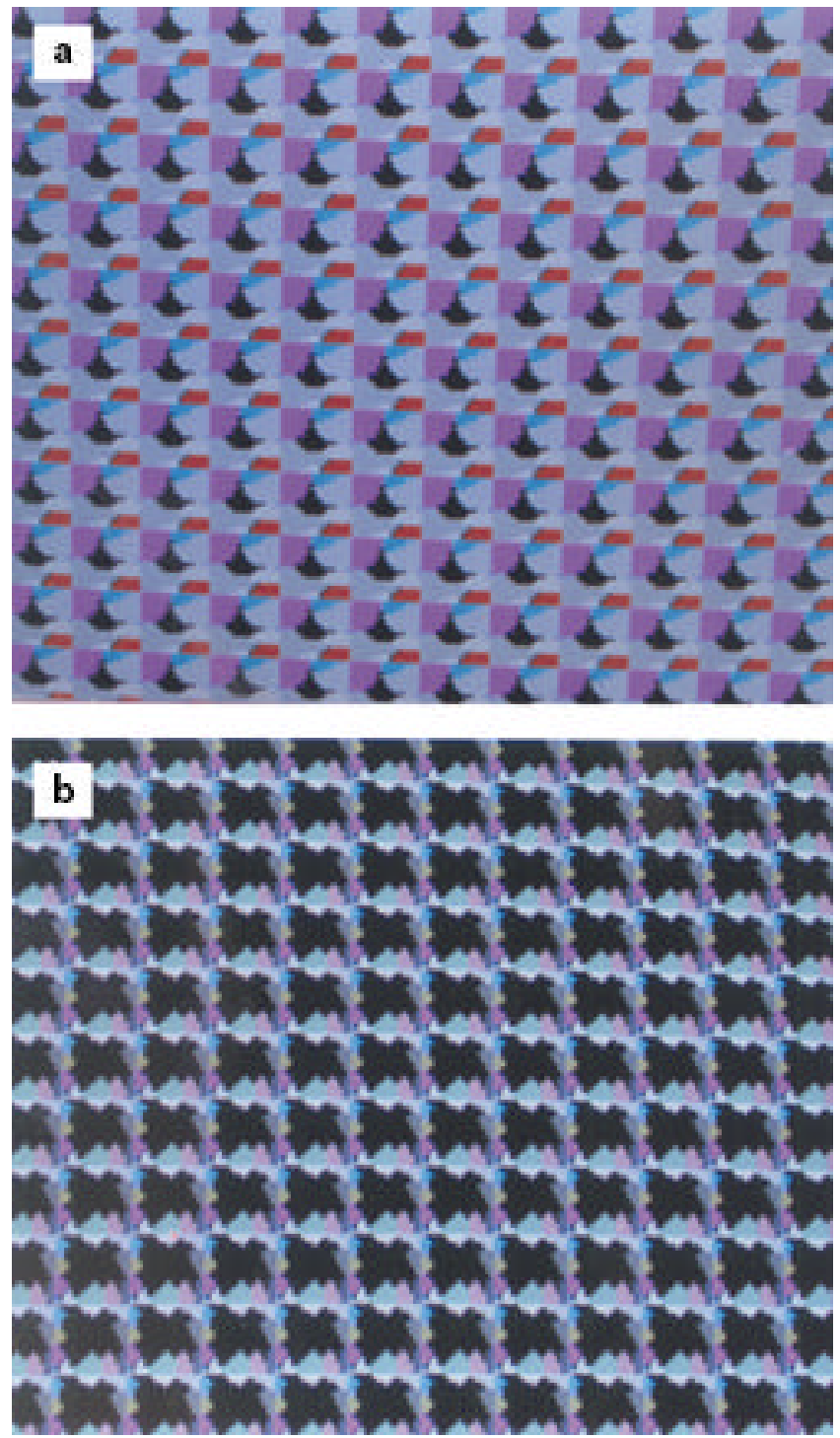

Figure 10. a. Simulated microstructure for cooling rate $10^{\circ} \mathrm{C} / \mathrm{S}$, simulated equivalent grain diameter $d_{\alpha}=8.2 \mu \mathrm{m}$ and b. simulated microstructure for cooling rate $60^{\circ} \mathrm{C} / \mathrm{S}$, simulated equivalent grain diameter $d_{\alpha}=2.55 \mu \mathrm{m}$.

red etc based on the nucleation identification number. The simulation domain is a single austenite grain, and this unit was repeated several times, to get the microstructures given in figures $10 \mathrm{a}$ and $\mathrm{b}$ for 2 different cooling rates (Kumar 2000). It can be seen from figures 10a and $\mathrm{b}$ that as the cooling rate is increased, the number of ferrite grains nucleated also increases, but the fraction of austenite transformed decreases as seen in the experiments.

\section{Conclusions}

A two-dimensional model describing the austenite decomposition into ferrite and pearlite has been developed. It is possible to simulate the kinetics and the microstructural evolution during transformation of austenite 
into ferrite and pearlite under isothermal and continuous cooling conditions. At this stage the model deals with binary $\mathrm{Fe}-\mathrm{C}$ alloys only and is two dimensional in nature. Therefore, experimental comparisons with real steels do not show precise quantitative agreement. However, the qualitative predictions point to the essential soundness of the model and show that with modifications and increased computing power the model can serve as a basis for a powerful tool for simulating the transformation of austenite.

\section{References}

Agarwal P K and Brimacombe J K 1981 Metall. Trans. B12 121 Andrews K W 1965 J. Iron Steel Inst. 203721

ASTM 1977 ASTM standard E-112, Austenite grain size measurement

Campbell P C, Hawbolt E B and Brimacombe J K 1991 Metall. Trans. A22 2769, 2778, 2791

CLEMEX Technologies 1998 Clemex Vision Users Guide, version 2.2, Quebec, Canada
Denis S, Farias D, Simon A and Bech G 1985 Mater. Sci. Technol. 1805

Denis S, Sjostorm S and Simon A 1987 Metall. Trans. A18 1203

Denis S, Farias D and Simon A 1992 ISIJ Int. 32316

Hawbolt E B, Chau B and Brimacombe J K 1985 Metall. Trans. A16 565

Hillert M 1957 Jernkont Ann. 141757

Kumar M, Sasikumar R and Kesavan Nair P 1998 Acta Mater. 466291

Kumar M 2000 Modelling of microstructure evolution during transformation of austenite to ferrite and pearlite, $\mathrm{Ph} . \mathrm{D}$. Thesis, Indian Institute of Technology, Madras

Kurtz W and Fisher D J 1986 Fundamentals of solidification (Switzerland, Germany: Trans. Tech. publications) p. 164

Militzer M, Pandi R and Hawbolt E B 1996 Metall. Trans. A27 1547

Munirajulu M, Dhindaw B K and Biswas A 1994 Scr. Metall. Mater. 301037

Thevoz Ph, Desbiolles J L and Rappaz M 1989 Metall. Trans. A20 311

Zener C 1946 AIME Trans. 167550 